\title{
Shaping the Boundaries of a Service Ecosystem: The Case of Udacity
}

\author{
Hannes Rothe \\ Freie Universität Berlin \\ hannes.rothe@fu-berlin.de
}

\author{
Florian Steier \\ Freie Universität Berlin \\ florian.steier@fu-berlin.de
}

\begin{abstract}
Service-dominant logic highlights the ability of service ecosystems to 'self-adjust' as a reaction to systemic inefficiencies or external changes [1]-[3]. We contribute to the question on how focal actors shape the boundaries of service ecosystems through service innovation. This is a single case study on a digital ecosystem focused on a first mover in digital platforms for Massive Open Online Courses (MOOCs): Udacity. We found two mechanisms, where Udacity shaped the boundaries of its ecosystem: 'user self-service integration' and 'gradual partner disintegration'. Throughout three phases between 2011 and 2015 they disintegrated services from higher education, namely offering courses online, designing course, and accreditation due to lowly perceived adaptability of universities and external pressures for finding a sustainable business model. Additionally, they disintegrated self-organized solutions of user needs and re-integrated them with new actors. This led to newly shaped boundaries of the service ecosystem.
\end{abstract}

\section{Introduction}

'In the beginning we tried to work with universities and anybody who does an education startup, think twice. Because you are dealing with a super glacially slow system. [...] Then we went the gutsy way and said, let's ditch all the university, essentially. ' [4].

2011 was the year, when founders of Udacity published a course about Artificial Intelligence freely on the web and attracted more than 160,000 participants. According to New York Times information, Anant Agarwal, CEO of edX, called the following year 2012 the 'year of disruption' [5] for the educational sector. Massive Open Online Courses (MOOCs) are educational services based upon information and communication technologies (ICT). Single institutions seldomly design, deploy, distribute and use these courses completely on their own. Instead, they reflect types of 'business model innovations for educational services that are increasingly realized within digital value cre- ation networks' $[6, \mathrm{p} .112]$. MOOC platforms are oftentimes at the heart of these services. Sebastian Thrun, who started the first MOOC of this kind and founded Udacity, stated in 2011, that he wanted to 'bring education to places that can't be reached today, to people that haven't had access to higher education' [7]. These platforms changed throughout the years of introduction, initiating several service innovations in the field of higher and further education. These changes finally led to a situation in 2013, where Udacity's founder Sebastian Thrun called his own MOOC platform a 'lousy product' [8]. While heavily relying on value co-creation with actors from higher education as an integral part of Udacity's service offering, the composition of Udacity's service ecosystem changed gradually. By September 2015 Udacity offered 88 MOOCs (27 of them with more than 50,000 learners). Many of them, with lecturers from private companies.

We build on system-theory and choose a (critical) realistic perspective [9] to assess how a digital service provider shaped the boundaries of its service ecosystem through service innovations. In order to form generative mechanisms we use a longitudinal, exploratory research design as proposed by [10] in qualitative-abductive single case study about the first mover for MOOC platforms. We analyze the content of more than 700 articles from public media, press releases, video statements and the platform itself to reveal events and activities by Udacity and related actors from 2011 to 2015 . To triangulate the data we analyze public video statements from founders and investors of Udacity. As a result, we describe a two generative mechanisms of service disintegration and re-aggregation by a digital platform in an educational domain.

\section{Service Ecosystems}

Even though service-dominant logic (sd-logic) can hardly be called a 'new' paradigm anymore, it is still thoroughly discussed in service management and information systems (IS) research [2], [11]-[13]. Sd-logic was initially founded on eight [11] and has later been extended to ten premises [12]. Meanwhile these premises have been rearranged and centered around four axioms [1], [3]. Each premise can be derived from these axioms: (1) 'Service is the fundamental basis of exchange', (2) 'The customer is 
always a co-creator of value', (3) 'All economic and social actors are resource integrators', and (4) 'Value is always uniquely and phenomenological determined by the beneficiary'. The value co-creation concept lies at the core of these premises. It describes the reciprocal integration of resources between actors through interactions [3], [14].

In the past, sd-logic has already been linked to network theory, relying on the concept of an actor-to-actor 'value network' [15]. This concept was extended by highlighting the systemic character of these "value networks' through the concept of service ecosystems [16]. Vargo and Lusch [3] describe service ecosystems as 'relatively self-contained, self-adjusting systems of resource-integrating actors that are connected by shared institutional logics and mutual value creation through service exchange.' Each actor is a potential source of resources for other actors within the ecosystem [17]. Value co-creative interaction describe interrelations between these actors in an ecosystem. General system theory - a theoretical pillar of the service ecosystem concept [18] - is concerned with describing the interrelations between elements of a system, their input, output, and throughput as well as the boundaries of a system [19].

The environment is a constitutive attribute of a system. According to Luhmann [20], a description of interactive behavior between elements in a social system is a major parameter to discern between internal and external elements. Following his argument, an (autopoietic) system reacts to events of its environment through adaptive behavior of the elements within the system to create itself anew. As we said before, value co-creation constitutes the interaction between actors within a service ecosystem. Analogous, service ecosystems are able to adjust through quickly responding and evolving actors who are loosely coupled [1], [3]. Changes in relationships between two actors may also affect other actors, as these changes ripple through the network and impose a self-adjusting character of an ecosystem [1].

In its core, the service ecosystem concept has closely been related to service system literature [18], which describes the nature of services as a 'dynamic value co-creation configuration of resources' [21] through interdependent value propositions. Service ecosystems' mainly distinguishable character from service systems is their open nature. The system enables actors to improve their current state by integrating external resources [18], in this case, the creation of weak ties [22] (or loose coupling) through activities of value co-creation with new actors. Hence, shaping the boundaries of a service ecosystem entails a redefinition of the identity of systemic actors and behavior by other actors in the ecosystem, which leads to the inclusion or exclusion of services from this ecosystem.

Literature on service innovation is explicitly concerned with an actor-specific beneficial rebundling of diverse resources in order to create new resources [13]. Sdlogic also assumes that each actor in an actor-to-actor-network shares, transfers and integrates resources as long as this seems to be subjectively beneficiary. Hence, service innovations regularly occur in co-creational processes.

This paper focuses on digital services. ICT is at the core of these service offerings. Technology is discussed as a moderator of value creation processes [1], [23]. It enables ties between actors in an ecosystem and mainly contributes to value creation as a resource on which other resources can be operated - so called, operant resources. Based on these ties and due to the underlying principle of standardization and automation, digital services can be more easily disintegrated into multiple, or re-aggregated into single services [2], [24]. Service ecosystems consist of various resource-integrating actors, who choose freely which resources they use and whom they involve in value co-creation process. Hence, a focal service provider may find expected as well as unexpected actors and interactions as the service ecosystem evolves [2].

Prior publications already focused on certain types of interrelations between a service ecosystem and service innovations. Some authors focused on the co-creation of service innovation between customers and focal firms [23], [25]-[28]. Others concentrated on the importance of inter-organizational ties in collaborations for service innovation [26], [29]. Research on how service ecosystems 'self-adjust' is nonetheless scarce. In the following, we present a single case study of a service ecosystem centered by a digital platform service who redefines the way its 'resource-integrating actors' [3] mutually co-create value.

\section{Case Study: Udacity}

\subsection{Research Method}

In order to reveal potential self-adjustments of a service ecosystem by its actors, we exploratory depict a process on contemporary events. As proposed by Yin [30], we subsequently perform a case study research. According to him, single case studies are especially useful if the case in question is critical, unusual, common, revelatory, or longitudinal. As will be shown in the following chapter, Udacity was a first mover in the field of MOOCs in higher education. Later on, Udacity shifted its initial business model dramatically towards addressing further education. It is therefore a revelatory, longitudinal and critical case.

The foundation of our single case study consists of 732 news articles and news releases that were published between February 2012 and September 2015. We analyze 
about 3 hours of public video material of Udacity's founders and investors to complement this data set in order to triangulate key statements. We collect media data with Lexis Nexis and analyze it with Atlas.ti. Articles are coded using an actor-centric perspective. To assess Udacity's service ecosystem we assess value co-creation behavior between the MOOC platform and other actors, in form of mutual value propositions. We intend to explore behavior, that led to the inclusion of new, or the exclusion of current actors. For this purpose, we categorize events and actions according to a business model typology adapted from the Business Model Canvas [31], [32]. This typology centers economic behavior on value propositions of an actor and relates it to key activities, key partners, key resources, (customer) channels, customer support, revenue streams and costs. Using articles from public media inhibits the study, as we are only vaguely able to assess internal actions by Udacity, like costs and key resources. We diminish this constraint partly by triangulating the data with public statements of Udacity's founders, investors and partners.

Since the concept of key partners directly relates to actors in a service ecosystem, we discern between $a c$ tors directly connected to Udacity (e.g., learners, universities and partners) and indirectly connected actors (e.g., competitors). Even though imitation from competitors is a common motive to choose a business strategy, actions by competitors may have directly influenced customers or partners by rippling down the service ecosystem. Subsequently, we also code actions of competitors, as they potentially had an indirect impact on Udacity's activities.

We refine the coding scheme and draw empirical findings following an abductive qualitative research process. In order to describe the process of Udacity's activities between 2011 and 2015 we use temporal bracketing [33] throughout our study. As a result, we divide the case into three phases. Each phase describes a preferably homogeneous and continuous sequence of events which allow for differentiation between those phases [33]. In addition to this secondary data set, we collect data on the course offerings from Udacity's web page retrospectively for each phase using the Internet Archive (www.archive.org). We use data about lecturers, their respective company, course data, and degree information to create actor-to-actor networks between individuals and organizations in the service ecosystem for each phase. Due to data restrictions, information about students' numbers are only available for the third phase.

This research thrives to look at the self-adjustment of an autopoetic ecosystem. We assume creating (and participating) in courses as the continual process, necessary for a self-reproduction of an ecosystem [20].
Actors who give lectures therefore represent a core element of the service ecosystem. To illustrate the development of the ecosystem with regards to this core activity, we present graphs of the actor-to-actor network on a micro-level, also referred to as an ego-network [34], [35]. Each circular network - depicted on the following pages - represents a compilation from Udacity's ecosystem with respect to alters also participating in the core activity of giving courses and being responsible for the MOOC content. Each node represents an organization and each tie a joint course offering between members of these organizations. The size of each node illustrates the number of employees engaged in these courses as well as public collaborations on course offerings between Udacity and the institution in question.

The following chapter gives an overview about the case of Udacity using temporal bracketing. For this purpose, we focus on a depiction of focal public actions of Udacity, and events influencing its related service ecosystem from 2011 to 2015.

\subsection{How to Create a MOOC Platform and Overcome a 'Lousy Product'}

3.2.1. First Phase (July 2011 to July 2012) “We believe university-level education can be both high quality and low cost." (First line of Udacity's 'about us' page in 2012 on [36])

Udacity's value proposition: Sebastian Thrun and Peter Norwig published their course CS221: Introduction to Artificial Intelligence in the winter term 2011. It was freely available on the web. About 160,000 learners from 190 countries joined their MOOC. Originally, the course was given in English. Shortly afterwards Thrun left Stanford University to concentrate on founding a MOOC platform in January 2012, called Udacity. According to the news releases, it was his aim to '[...] bring education to places that can't be reached today, to people that haven't had access to higher education" [7] and "[...] making education available to the entire world [...] absolutely free of charge' [37].

Udacity's key activity: The first courses were offered in February 2012. As a former Stanford-professor and Google manager Sebastian Thrun was able to offer these courses largely by himself or with former colleagues from the university. Each MOOC focused mainly on technology-related content, like web service engineering, cryptography or building a search engine. Hence, courses were mainly offered by lecturers from universities (see fig. 1, left frame).

Target group: Udacity explicitly addressed learners from all ages and with a variety of prerequisites, including students with or without prior IT knowledge, employees from different professions as well as elderly. It especially focused on BRIC countries to impact lives around the 


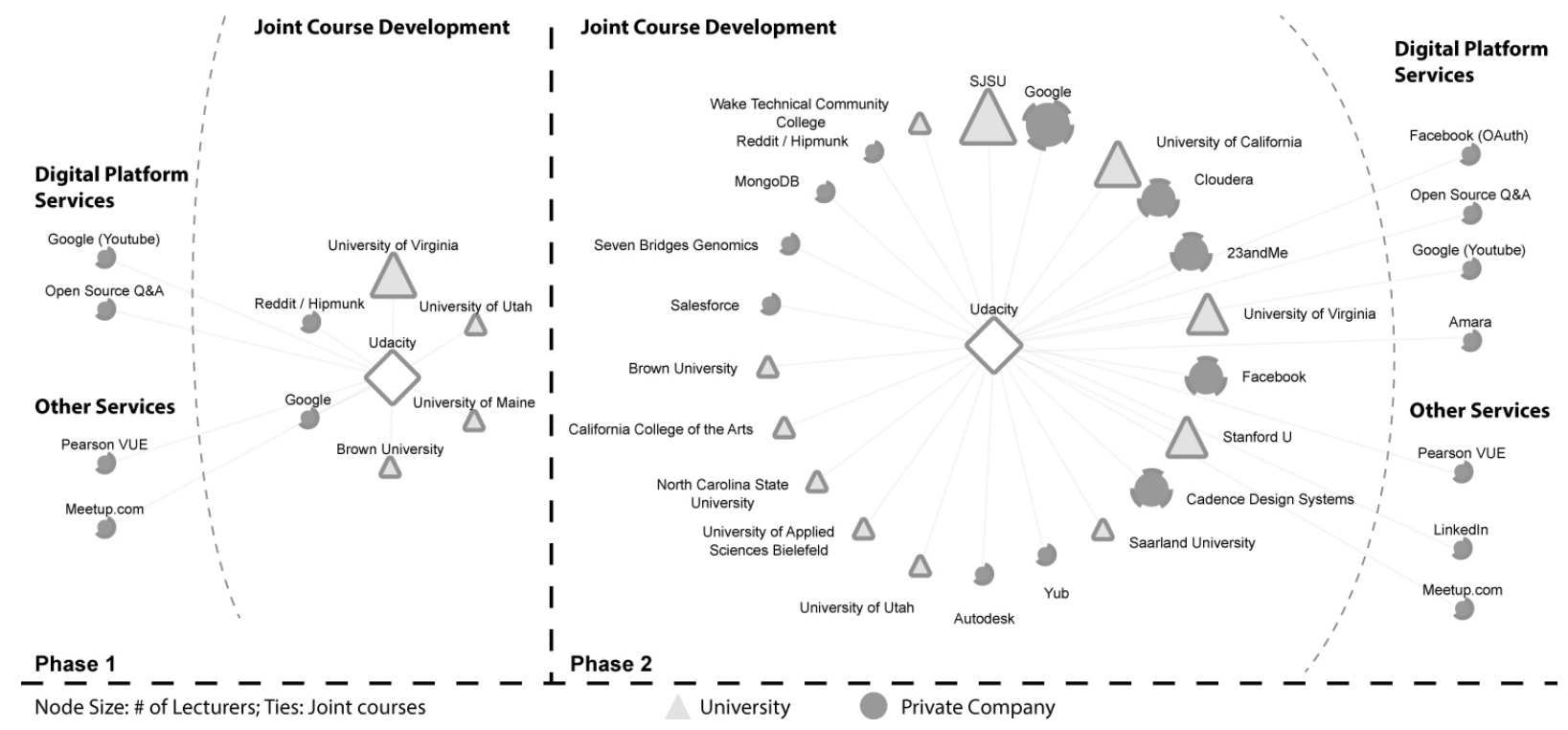

Figure 1. Service ecosystem related to designing MOOCs on Udacity in $1^{\text {st }}$ and $2^{\text {nd }}$ phase

world, for the next billion students from China and India' [38].

Customer channel and support: An automated system supported learning processes, which heavily relied on video lectures and multiple-choice questions. Instead of publishing these videos freely on Youtube, Udacity later integrated them into its own platform. Peer-to-peer-interaction in live chats, on online discussion boards, and self-organized live meetings on Meetup.com facilitated basic support for questions and issues. By implementing parts of these services on their own, partnering with Open Source Q\&A, and the official partnership with Meetup.com Service, these functions were integrated into Udacity's platform meanwhile. Student groups also met in person by creating local Meetups.

Revenue stream: The course offering was free to learners. In March 2012, Udacity made first attempts to commercialize its recommendations of these 'thousands of students who have learned these [machine learning] skills' [39] to recruiters worldwide. However, after July 2012 the MOOC platform gained profits mainly through verified exams. This shift of strategy sets the frame for Udacity's second phase.

Directly tied actors: After publishing the course on Artificial Intelligence, some learners unexpectedly translated the content into 44 other languages using a service called Amara. Furthermore, they opened up discussion boards on their own.

Besides having intensive relationships with individual professors throughout the initial phase, Udacity did not directly cooperate with universities on an institutional level. To accredit students' activities despite that, they formed a partnership with Pearson VUE. As a global partner, Pearson was able to offer offline test centers for learners on a global scale. Udacity integrated accreditation into its main services and priced each verified exam with $89 \$$ at the end of this phase.

Public media more and more compared Udacity's activities to traditional universities and noticed the comparative cost advantages of MOOCs from 3,000\$ (Stanford) to $1 \$$ (Udacity)[37] per student, which may strike risks especially for institutions with medium or low reputation[40].

Indirectly tied actors: Platform competitors entered the newly founded MOOC market shortly after Udacity's founding. MIT created MITx in March and merged their platform service with Harvard in May, renaming it into edX. Two former colleagues of Thrun, Andrew $\mathrm{Ng}$ and Daphne Koller, formed Coursera in April. Other competitors, like Minerva and Udemy, followed shortly afterwards. Udacity's highest competition came from Coursera. They initiated relationships with the University of Michigan, Pennsylvania, Stanford U and Princeton U. Another twelve universities followed in July 2012. Even though Coursera's number of relationships with universities rose, they did not create direct profits in this early phase, either.

\subsubsection{Second Phase (August 2012 to December 2013)} "Our mission is to bring accessible, affordable, engaging, and highly effective higher education to the world. We believe that higher education is a basic human right, and we seek to empower our students to advance their education and careers." (Udacity's mission statement 2013 in [41])

Value proposition: In the first phase, Udacity explored mainly the technical and didactical basis of a MOOC platform. A major task of the second phase for all platform 
offerings can be described as finding steady revenue streams and legitimizing the platforms in the educational system (mainly in the US). While its value proposition on bringing education to the whole glob - including rural areas - has been sharpened at first, conflicts within the ecosystem arose. This led Sebastian Thrun to declare the way Udacity offered MOOCs until December 2013 a 'lousy product' [8]. Concurrently, he announced to pivot the business model, no longer addressing higher, but further education in the future.

Key activities: By December 2013, Udacity offered 33 courses on computer science, physics and business administration.

Target group and customer support: At the end of this phase, Udacity was confronted with high dropout rates and noticed a growing misfit between their services and the target group. Many learners 'didn't have computers and high-speed Internet [sic] connections at home that the online course required' [42]. Their MOOC topics, the technology adapted by Udacity as well as a lack of intensive support did not necessarily match to early student target groups, especially in BRIC countries. Udacity experienced a misfit in their current target group perception, as 'about 80 percent of those taking the university's MOOCs had already earned a degree of some kind' [43]. Those students ask for advanced training in cutting-edge methods and technologies in order to raise their employability.

Directly tied actors: Translation of the courses that allowed internalization was unexpectedly organized and fostered by learners in the first phase. Until February 2012, 'volunteers have translated more than 1,200 videos, all through a grassroots movement started by students for students' [44]. This led to an official partnership between Udacity and the translation platform Amara adding further customer support.

A joint partnership with LinkedIn (and the other MOOC platforms) to add "direct-to-profile certification" at the end of this phase already displays a new paradigm on raising and showing employability through MOOC participation.

As the first university of the United States, Colorado State University offered credits for students of their curricula, who participated in a MOOC (on Udacity). For this purpose, students took exams held in Pearson test centers. Udacity extended their university-partnership gradually during this phase. In January 2013, Californian governor, Jerry Brown, announced a cooperation of San Jose State University (SJSU) and Udacity to offer a complete online degree program. In March 2013, the proposed Senate Bill 520 was meant to open the possibility for universities to complement their current course offering with MOOCs, if students 'could not get a seat in the course they needed' [45].
Simultaneously, the tendency towards integrating MOOCs into university's curricula led to an upcoming critique from professors and university employees. They remarked a standardization of learning processes, and a lack of interactions between educators and learners, which subsequently leads to a diminished educational quality. High dropout rates of MOOC participants supported their argument. This culminated in an open letter from the philosophical department of SJSU to Michael Sandel (Harvard) in April 2013. Additionally, professors remarked that cost reductions in higher education may be 'used as an excuse for state legislatures to cut funding to state universities' [46]. Hence, '[p]rofessors who care about public education should not produce products that will replace professors, dismantle departments and provide a diminished education for student in public universities' [47]. Lecturers and unions opposed MOOCs more openly during this phase [48]. The public perceived Udacity as a front-runner of the MOOC movement, and it attached critique on these course types oftentimes to Sebastian Thrun and his company. As conflicts with universities rose in public media and private messages, Thrun perceived himself as 'the most hated professor of America, because every other professor was fearing for their job' [4]. Finally, Udacity and SJSU suspended their collaboration on joint courses for a semester and did not extend its collaboration to further courses.

Later this year, in May 2013, Udacity announced an online degree program with Georgia Tech. They wanted to evaluate the question whether MOOCS can 'make education more affordable and help diffuse online media into higher education' [48]. Within this cooperation, and for the first time, they directly collaborated with a private company on a course offering: AT\&T. They followed a strategy Thrun already explained in December 2012 [49]. According to Thrun, 'new technologies come on to the market at a very fast pace today and the universities can't keep up. So they [the companies] want us [Udacity] to step up and help' [50].

Due to perceived lacks of adaptability to learners' and company's demands from traditional university teaching, Udacity began to exploit experiences with online learning and their platform. The cooperation with AT\&T, as well as their direct financial backing of about 2 million $\$$ ' $[\ldots]$ embark on a new era for higher education and for the development of a highly skilled work force' [51].

Indirectly tied actors: In September 2012, edX followed Udacity's lead to cooperate with Pearson VUE to make use of their test centers. Coursera on the other hand collaborated directly with universities to offer accredited exams at their campuses. By the end of 2012, Coursera already had twice the user base of Udacity. In May 2013, they announced 5 Mio learners on their platform. One explanation of the comparable success is the variety of topics taught by the 204 courses on Coursera at this time. 


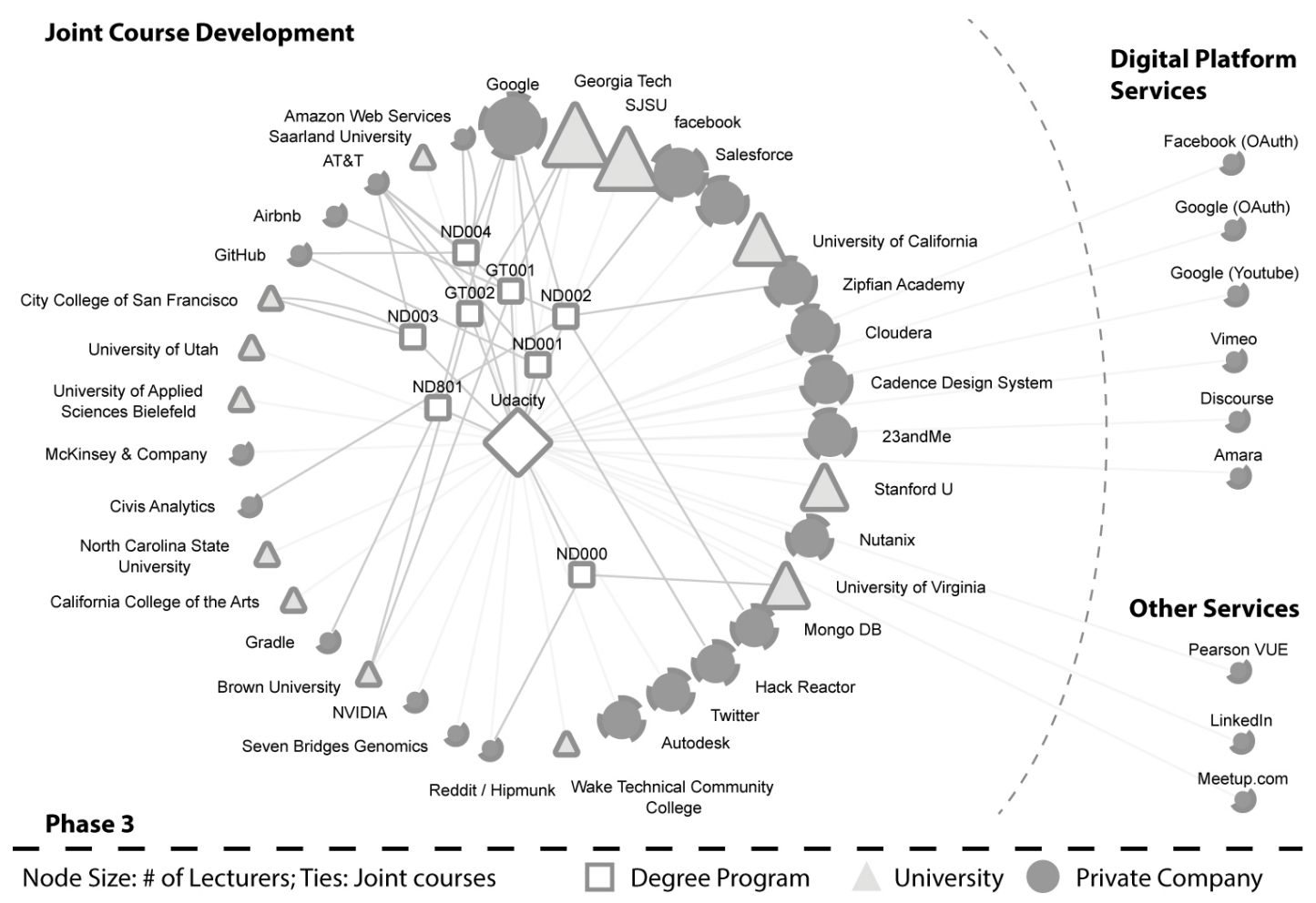

Figure 2. Service ecosystem related to designing MOOCs on Udacity in $3^{\text {rd }}$ phase

They also launched a mobile application by the end of the second phase as a new customer channel. Furthermore, Coursera - as well as edX - created licensing models for universities to use the platform as an internal course management system. EdX also commercialized subservices, like course translations and technical consultancy, for universities.

\subsubsection{Third Phase (January 2014 to September} 2015) '[...] Education is no longer a one-time event but a lifelong experience. [...] Education should empower students to succeed not just in school but in life, (Addition to the mission statement in 2015 on [52])

Value proposition and target group: A third phase (January 2014 to September 2015) of this case study was initiated by two events. Sebastian Thrun stated to pivot Udacity's business model at the end of 2013 towards further education in a technology related field. Therefore, they created Nanodegrees, a valued credential that raises employability. This new value proposition was set up for learners who long for knowledge and competences in a technology-related profession, which guarantees a subsequent job entry in this field.

Key activities: At the beginning of this phase, Georgia Tech, AT\&T and Udacity launched their prior announced online degree program. Supported by about 35 million \$ from investors, Udacity secured the financial backup to creating further online degrees - called Nanodegree - either with private companies or on their own. Throughout this phase 57 courses were created. Additionally, Udacity began to create and offer more courses completely on their own (19 courses, opposing three in the second phase, and two in the first).

Customer channels and support: In order to reach their target group, Udacity complemented its web platform by an iOS and an Android app for engaging with learners on mobile devices. It was their expressed hope, that caching learning materials locally on a mobile device would lower entry barriers for users who do not have steady internet access. They found this to be a critical need for learners in the global south. Additional customer support was offered to students within their Nanodegree program (see below). Furthermore they reacted to new requirements to their discussion board, especially with regards to a growing amount of spam messages, by changing their open source platform OSQA for Discourse. With the addition of new Nanodegrees, Udacity also emancipated partly from Youtube, by adding Vimeo to the service ecosystem.

Revenue stream: Udacity acquired new revenue streams by partnering with Georgia Tech and private companies. The new Nanodegree program is built upon a subscription model (200\$/month for a year). The Online Master Degree creates 6,600\$ per student for Udacity and Georgia Tech. To gain an individual certificate from Georgia Tech costs $399 \$$ per course. 
Directly tied actors: In January 2014, Udacity, Georgia Tech and AT\&T launched their first joint degree program. Participants of the Online Master program got additional access to tutors and projects from Georgia Tech. Students within the individual certificate program were able to contact professors and partake official exams.

In June 2014, Udacity initiated their Nanodegree program in cooperation with several private technology-related companies (see table 1). They used these partnerships to design an online curricula 'by business for the specific skills that are needed in business' [53]. AT\&T helped Udacity explicate their new value proposition by offering 'up to 100 paid internships for nanodegree graduates'[54]. According to Udacity the motivation of learners heading for a Nanodegree show '[...] double the engagement, double the progress, more than double the retention rate' [55]. About 7000 users registered for a Nanodegree by February 2015. Each learner spent six to nine months until completion.

Table 1. Degree partners in the $3^{\text {rd }}$ phase

$\begin{array}{ll}\text { Degree Name } & \text { Degree Partners } \\ \begin{array}{l}\text { Online Master of Science in } \\ \text { Computer Science } \\ \text { Georgia Tech Degree Certifi- } \\ \text { cate Program }\end{array} & \text { AT\&T, Georgia Tech } \\ \text { Introduction to Programming } & \text { No additional partner } \\ \text { Front-End Web Developer } & \begin{array}{l}\text { AT\&T, Google, Hack Re- } \\ \text { actor, GitHub }\end{array} \\ \text { Data Analyst } & \begin{array}{l}\text { Google, MongoDB, Face- } \\ \text { book, Zipfian Academy }\end{array} \\ \text { iOS Developer } & \begin{array}{l}\text { AT\&T } \\ \text { AT\&T, Google, Amazon } \\ \text { Full Stack Web Developer }\end{array} \\ \text { Web Services, GitHub } \\ \text { Android Developer } & \text { Google }\end{array}$

Within the third phase, Udacity largely decoupled from university collaborations in favor of diverse and intensive partnerships with technology-related companies, like Google, Salesforce, Cloudera and AT\&T. Many employees of the platform (co-)tutored university courses on the platform before. Now they offered the technical knowledge and skills acquired until this point to firms. For the new courses they took over the design and implementation of the courses with partners from private companies instead. From this point on, Udacity publicly branded newly developed and already existing courses co-created with private companies and universities as "created by [company]".

Indirectly tied actors: Coursera (Specializations) and edX (XSeries) introduced online degrees at the beginning of 2014. For this purpose, university partners compiled multiple MOOCs into their programs. In addition, they kept a freemium model.
Both platforms offered single MOOCs freely available for learners. They only had to pay fees for verified exams. As part of these so-called Signature Tracks, Coursera explicitly turned towards further education for internal use of private companies in 2014.

\section{Case Summary and Conclusion}

\subsection{Two Mechanisms of Reshaping a Service Ecosystem}

As the case study shows, we found three phases in which Udacity gradually changed the collection of actors participating in co-creation activities of its core services. In its first phase Udacity launched a platform service to offer knowledge openly and freely to learners from all over the world. For this purpose they collaborated with universities. Individual lecturers and whole institutions were invited to join in designing and offering courses to their students. In parallel, Udacity needed to develop a value proposition related to a sustainable revenue model, which led to the introduction of certificates following a freemium concept.

Throughout the second phase, they experienced institutions in higher education as being too slow, to answer the needs articulated by paying learners and private companies. They struggled with university partners and moved towards integrating private companies more deeply into their core activities. After calling its own service offer a 'lousy product', the MOOC platform pivoted. The target group was narrowed down towards people in further education who reach out for technology-related professions and fostering employability. Within both phases, new actors were integrated into the service ecosystem to keep up the service offer. In order to subsume changes of actor constellation and resource allocations, we form two generative mechanisms [10]. These explain how a value co-creative process of designing MOOCs in the ecosystem led to the integration of formerly external actors, we call them (1) 'user self-service integration', and (2) 'gradual partner disintegration'.

If users perceive a lack with their current service exchange, some of them solve these issue on their own. 'User self-service integration' describes a mechanism, where solutions are recognized by a focal service provider and integrated as part of its value proposition - either by adding it to its own key activities or integrating it with the help of new actors. We found two occasions for this mechanism. Learners in MOOCs co-create value as they intentionally and unintentionally enrich Udacity's educational service offer and data sets - not only through peerto-peer-tutoring. While Udacity's founders initially disintegrated the traditional university lecture into a video stream that was uploaded by a few lecturers to the web, (1a) students created complementary discussion boards 
and live meetings throughout the first phase. Later on, Udacity integrated these resources through internalization of video streaming, content distribution and online discussion functions into its own MOOC platform. For this purpose, they adapted external services, from YouTube (Vimeo), Meetup.com, Open Source Q\&A, and Discourse to their platform. (1b) Learners also improved the video and text-based content by unexpectedly translating subtitles on their own. Udacity reacted in the second phase, as they officially partnered with the crowd-translation platform Amara.

In cases where a focal service sees current service exchanges as inferior, it may choose to follow a ' $\mathrm{grad}$ ual partner disintegration' in order to acquire resources from an external actor, instead. Relationship between Udacity and its university partners went from complementary to substitutive over the time observed in this case study. Within the first phase Udacity's value proposition mainly complemented university offering within their core market (higher education). Universities offered the content, Udacity published it to a large target group on the web and gave technical support. (2a) But unlike edX or Coursera until this point, Udacity began to substitute one of universities core value propositions - accreditation and examination - with the help of a private company partner, Pearson VUE. Within the second phase, Udacity initiated partnerships with universities to offer online degrees. The degree itself was still accredited by the universities. Their first try to make MOOCs part of university curricular with SJSU was nevertheless suspended at first and not further extended later on. With the beginning of its third phase Udacity partnered with Georgia Tech to offer a full online master's degree. Since 2014 no extensions to university collaborations were scarce. Instead, Udacity laid the foundation to further disintegrate this resource from higher education by substituting traditional degree programs, they call Nanodegree.

As Udacity directly complemented more and more of universities core services, public media and individual professors criticized high dropout rates and their perception of low educational quality. Competitors, like Coursera, offered by far more MOOCs with the help of a multitude of professors from a variety of universities across the US - and beyond both oceans. Hence, we could assume that the perceived influence on the debate on educational quality of MOOCs may also be influenced by competitor's actions. We assume from the discussion within the media and Sebastian Thrun's retrospective statements, that the ongoing debate about dropouts and the lack of quality of MOOCs in general had an impact on Udacity's decision to change their value proposition towards targeting academics and professionals.
Table 2. Course and partner development

\begin{tabular}{|c|c|c|c|}
\hline & se 1 & Phase 2 & Phase 3 \\
\hline $\begin{array}{l}\text { No. of } \\
\text { Courses }\end{array}$ & 11 & 33 & 90 \\
\hline \multicolumn{4}{|c|}{ Number of Lecturers per Institution } \\
\hline Company & 2 & $19(+17)$ & $51(+32)$ \\
\hline University & 6 & $22(+16)$ & $34(+12)$ \\
\hline Udacity & 6 & $15(+9)$ & $33(+18)$ \\
\hline Sums & 14 & 56 & 118 \\
\hline
\end{tabular}

(2b) In parallel, Udacity began collaborating with private companies in the field of ICT on the content of a MOOC. Instead of deeply integrating university employees and professors into their MOOC service offering, Udacity partnered with 'industry leaders', like Google, Facebook, Salesforce, NVIDIA, mongoDB, and AT\&T, in the third phase (see table 2). Competitors, like Coursera or edX, also integrate industry partners into their Specializations from time to time. In comparison, their platforms nevertheless always set individuals from universities into the heart of their MOOC programs. In contrast, Udacity co-created its core services with private companies, as they set and design MOOCs and Nanodegrees. Furthermore, they provide case studies and exercises based on practical issues using their own services and platforms e.g., Android OS, Facebook Open Graph, or NVIDIA's CUDA platform on parallel computing - as course materials. In order to be able to teach these current and specific methods and technologies to a highly specialized target group, Udacity offered their accumulated knowledge and skillset in designing online courses with these firms. Thus, Udacity shifted towards further education and became less a complementary to universities, but aimed at becoming a substitute. They focused on raising employability. Their motivation was described as 'unbundling' higher from further education to prepare for a time, where having 'a PhD or an MA or even a BA won't be a job requirement' [56]. As a result, 57 out of 90 MOOCs were offered without any university participation by September 2015.

\subsection{Conclusion and Implications}

Agility and adaptability of actors ensures sustainability of a service ecosystem by fostering its ability on an elemental level to self-adjust in cases of external changes or restraints that lead to subjective inefficiencies [1], [13]. This case study explores self-adjustment in an educational service ecosystem. Creating online courses are described as autopoetic processes of self-production. By presenting the development of Udacity from 2011 to 2015, we exemplify two generative mechanisms that led to a reformation 
of actors in the ecosystem: (1) 'user self-service integration' and (2) 'gradual partner disintegration'. We exhibit how students, universities, and private companies - as actors within the service ecosystem - added resources to the ecosystem while creating MOOCs, that were disintegrated by a focal service provider at first and reintegrated, later on, with external actors. This focal service provider recognized users, who perceived a relevant demand and solved it on their own. Then it reintegrated this resource as part of a 'user selfservice integration'. Udacity integrated student-based discussion boards, translation services and local meetings with the help of new actors. Other core resources were reallocated from partners, which were perceived as being not adaptable, rigid or too slow as part of a 'gradual partner disintegration'. With regards to Udacity, the role from institutions in higher education as a complementary source of resources changed into becoming substitutive. They gradually replaced services from universities, like course content, design, and accreditation, with private firms. This paper sheds light on mechanisms of self-adjustment in service ecosystems [1], [13]. It extends our understanding of service rebundling [13], disintegration and reaggregation [2], [24] over time and how focal actors may use these to reshape the boundaries of a service ecosystem.

Especially due to limitations on external validity, we mainly hold managerial implications for the educational sector. The case study shows how the fields of higher and further education entangle over time. The capacity of companies to exploit new technologies by disintegrating key activities from partners (here universities) gives the opportunity to integrate new actors into an ecosystem. Even though power was only vaguely referred to in this article, we may presume, that especially platform owners want to explore strategies of fast (out)learning from partners with unique resources (here universities or lecturers), before supporting a process of gradual disintegration and reaggregation. As such, we may also shed light on possible extensions to a strategizing debate on digital platforms [57]. This is also a call onto service providers to spot and realize self-solutions by end users, not only of their own, but also for direct co-creators. Udacity was able to gain more control over otherwise concealed end user-activity, by partnering with crowd-translation organization Amara, Meetup.com, or by integrating discussion board applications into their digital platform after users solved related issues on their own.

\subsection{Limitations}

Even though Udacity may represent an exemplary case for a range of digital platforms that exist today, there are some limitations from using single case studies as a research method. Data collection and analysis focus on a MOOC platform. External validity is an inherent limitation of single case studies. Hence, we cannot directly subsume to generalized effects of all service innovations within digital ecosystems. Our set of publicly available data from media may contain opinions of their pertaining authors. Thus, we narrow data selection biases by using a diversity of (online and offline) press releases, video statements, and data collected from the Udacity platform itself for each phase.

\section{References}

[1] R. F. Lusch and S. L. Vargo, Service-dominant logic: Premises, perspectives, possibilities, 1st ed. Cambridge, United Kingdom: Cambridge University Press, 2014.

[2] M. Barrett, E. Davidson, J. Prabhu, and S. L. Vargo, "Service innovation in the digital age: key contributions and future directions," Mis Q., vol. 39, no. 1, pp. 135-154, 2015.

[3] S. L. Vargo and R. F. Lusch, "Inversions of servicedominant logic," Mark. Theory, vol. 14, no. 3, pp. 239-248, 2014.

[4] S. Thrun and G. Zachary, Sebastian Thrun \& George Zachary democratize higher ed w/Udacity; bonus: Jonathon Triest. This Week in Startups, 2016.

[5] L. Pappano, "The Year of the MOOC," The New York Time Education, 2012. . Available: www.nytimes.com/ 2012/11/04/education/edlife/massive-open-online-courses-aremultiplying-at-a-rapid-pace.html

[6] J. Wulf, I. Blohm, J. M. Leimeister, and W. Brenner, "Massive Open Online Courses.," Bus. Inf. Syst. Eng., vol. 6, no. 2, pp. 111-114, 2014.

[7] A. Raith, "Stanford for Everyone: More Than 120,000 Enroll in Free Classes," KQED News, 23-Aug-2011.

[8] M. Chafkin, "Udacity's Sebastian Thrun, Godfather Of Free Online Education, Changes Course," Fast Company, 14-Nov2013.

[9] M. Healy and C. Perry, "Comprehensive criteria to judge validity and reliability of qualitative research within the realism paradigm," Qual. Mark. Res. An Int. J., vol. 3, no. 3, pp. 118$126,2000$.

[10] K. McGrath, "The potential of generative mechanisms for IS research," 2013.

[11] S. L. Vargo and R. F. Lusch, "Evolving to a New Dominant Logic for Marketing," J. Mark., vol. 68, no. 1, pp. 1-17, Jan. 2004.

[12] S. L. Vargo and R. F. Lusch, "Service-dominant logic: continuing the evolution," J. Acad. Mark. Sci., vol. 36, no. 1, pp. $1-10,2008$.

[13] R. F. Lusch and S. Nambisan, "Service Innovation: A Service-Dominant Logic Perspective," MIS Q., vol. 39, no. 1, pp. 155-176, Mar. 2015.

[14] S. L. Vargo, P. P. Maglio, and M. A. Akaka, "On value and value co-creation: A service systems and service logic perspective," Eur. Manag. J., vol. 26, no. 3, pp. 145-152, 2008. [15] R. F. Lusch, S. L. Vargo, and M. Tanniru, "Service, value networks and learning," J. Acad. Mark. Sci., vol. 38, no. 1, pp. 19-31, 2010.

[16] S. L. Vargo and R. F. Lusch, "It's all B2B... and beyond: 
Toward a systems perspective of the market," Ind. Mark. Manag., vol. 40, no. 2, pp. 181-187, 2011.

[17] J. Pels and S. L. Vargo, "Toward a transcending conceptualization of relationship: a service-dominant logic perspective," J. Bus. Ind. Mark., vol. 24, no. 5/6, pp. 373379, 2009.

[18] H. Wieland, F. Polese, S. Vargo, and R. Lusch, "Toward a service (eco) systems perspective on value creation," Wieland, H., Poles. F., Vargo, S., Lusch, pp. 12-24, 2012.

[19] L. von Bertalanffy, General system theory: foundations, development, applications, 3. print. New York, NY CN

[20] N. Luhmann, Soziale systeme. Suhrkamp Frankfurt am Main, 1984.

[21] D. Gruhl, J. Bailey, J. Spohrer, and P. P. Maglio, "Steps toward a science of service systems," Computer (Long. Beach. Calif)., no. 1, pp. 71-77, 2007.

[22] M. S. Granovetter, "The strength of weak ties," Am. J. Sociol., pp. 1360-1380, 1973.

[23] M. A. Akaka and S. L. Vargo, "Technology as an operant resource in service (eco) systems," Inf. Syst. E-bus. Manag., vol. 12, no. 3, pp. 367-384, 2014.

[24] J. Fishenden and M. Thompson, "Digital government, open architecture, and innovation: why public sector IT will never be the same again," J. public Adm. Res. theory, vol. 23, no. 4, pp. 977-1004, 2013.

[25] M. Pynnönen, J. Hallikas, and P. Ritala, "Managing customer-driven business model innovation," Int. J. Innov. Manag., vol. 16, no. 04, p. 1250022, 2012.

[26] R. Agarwal, W. Selen, S. Sajib, and M. Scerri, "Dynamic capability building in service networks: An exploratory case study," J. New Bus. Ideas Trends, vol. 12, no. 1, p. 27, 2014.

[27] P.-F. Hsieh, C.-S. Lee, and J. C. Ho, "Strategy and process of value creation and appropriation in service clusters," Technovation, vol. 32, no. 7, pp. 430-439, 2012.

[28] J. Iden and L. B. Methlie, "The drivers of services on next-generation networks," Telemat. Informatics, vol. 29, no. 2, pp. 137-155, 2012.

[29] J.-S. Chen, H.-T. Tsou, and R. K. H. Ching, "Coproduction and its effects on service innovation," Ind. Mark. Manag., vol. 40, no. 8, pp. 1331-1346, 2011.

[30] R. K. Yin, Case Study Research: Design and Methods, 5th ed., vol. 5, no. 5. Thousand Oaks, California: Sage Publications, 2013.

[31] A. Osterwalder and Y. Pigneur, Business model generation: a handbook for visionaries, game changers, and challengers. Wiley, 2010.

[32] A. Osterwalder, Y. Pigneur, and C. L. Tucci, "Clarifying business models: Origins, present, and future of the concept," Commun. Assoc. Inf. Syst., vol. 16, no. 1, p. 1, 2005.

[33] A. Langley, "Strategies for theorizing from process data," Acad. Manag. R eview, vol. 24, no. 4, pp. 691-710, 1999.

[34] M. Lima, Visual complexity. Princeton Architectural Press, 2007.

[35] M. Everett and S. P. Borgatti, "Ego network betweenness," Soc. Networks, vol. 27, no. 1, pp. 31-38, 2005.

[36] Udacity, "About Us," udacity.com, 2012. . Available: web.archive.org/web/20120717184638/www.udacity.com/us. [Accessed: 25-May-2016].

[37] S. Thrun, University 2.0 (Sebastian Thrun, CEO at Udacity) | DLD12. 2012.

[38] T. Lewin, "Harvard and MIT join to offer web courses," New York Times, p. 18, 2012.

[39] D. Singh, "Make education industry relevant," The Pioneer, 2013.

[40] R. Blakely, "Google visionary revolutionises education with a degree course for the cost of getting online," The Times, 2012.

[41] Udacity, "About Us," udacity.com, 2013. . Available: web.archive.org/web/20131214090529/https://www.udacity.co m/us. [Accessed: 25-May-2016].

[42] K. Murphy, "San Jose State's online college course experiment reveals hidden costs," San Jose Mercury News, 2013.

[43] T. Lewin, "After Setbacks, Online Courses Are Rethought," The New York Times, 2013.

[44] G. Dekena, "Join the Udacity Translation Project!," Udacity Blog, 07-Nov-2012.

[45] K. Murphy, "California college students shut out of classes could earn credits online if new legislation passes," Bay Area News Group, 2013.

[46] M. Parry, "A Star MOOC Professor Defects - at Least for Now," The Chronicle of Higher Education, 2013. . Available: chronicle.com/article/A-MOOC-Star-Defects-at-

Least/141331/. [Accessed: 25-May-2015].

[47] Department of Philosophy (SJSU), "An Open Letter to Professor Michael Sandel From the Philosophy Department at San Jose State U.," The Chronicle of Higher Education, 2013. . Available: chronicle.com/article/The-Document-Open-LetterFrom/138937/. [Accessed: 25-May-2016].

[48] Thrun, Sebastian Thrun: Udacity - Konkurrenz für Hochschulen? Stifterverband für die Deutsche Wissenschaft, 2014.

[49] J. R. Young, "Providers of Free MOOC's Now Charge Employers for Access to Student Data," The Chronicle of Higher Education, 2012. . Available: chronicle.com/article/Providers-of-Free-MOOCs-

Now/136117/. [Accessed: 30-May-2016].

[50] S. Thrun, Reflections on online education: Udacity's Sebastian Thrun. McKinsey \& Company, 2013.

[51] S. Smith, "Harnessing the Power of MOOCs," AT\&T Cunsumer Blog, 2013.

[52] Udacity, "About Us," udacity.com, 2015. . Available: web.archive.org/web/20150706090126/https://www.udacity.co m/us. [Accessed: 25-May-2016].

[53] E. Porter, "A Smart Way to Skip College in Pursuit of a Job," The New York Times, 2014.

[54] AT\&T, "Efficient, Accessible, Affordable, Online Program Will Help Job Seekers Get High-Demand Technical Skills," AT\&T Newsroom, 2014.

[55] T. Dodd, "Udacity's nanodegrees link students to tech jobs," Business Review Weekly, 2015.

[56] K. Carey, "One vision of tomorrow's college: Cheap, and you get an education, not a degree," The Washington Post, 2015. [57] A. Ghazawneh and O. Henfridsson, "Micro-strategizing in platform ecosystems: a multiple case study," 2011. 